\title{
Two successful pregnancies after in vitro fertilisation with oocyte donation in a patient with Swyer syndrome - a case report
}

\author{
Aleksandra Urban ${ }^{1}$, Weronika Knap-Wielgus ${ }^{1}$, Monika Grymowicz ${ }^{2}$, Roman Smolarczyk ${ }^{2}$ \\ 'Students' Scientific Association, Department of Gynaecological Endocrinology, Medical University of Warsaw, Warsaw, Poland \\ ${ }^{2}$ Department of Gynaecological Endocrinology, Medical University of Warsaw, Warsaw, Poland
}

\begin{abstract}
Diagnosis of complete $X Y$ gonadal dysgenesis exposes the patient to the prospect of infertility and many years of medical treatment in order to avoid the development of diseases associated with this condition. However, sufficiently early diagnosis followed by the implementation of proper therapy improves the prognosis for enabling future pregnancies after IVF through the development of reproductive organs and prevention of health complications of hypoestrogenism such as cardiovascular problems and osteoporosis. This syndrome is very rare and affects 1 in 80,000 women. Due to the high risk of developing a gonadal tumour, prophylactic bilateral gonadectomy is one of the main procedures performed in a relatively brief time after diagnosis. Unfortunately, despite characteristic symptoms like primary amenorrhoea and underdeveloped breasts, the diagnosis is often made quite late. We report the case of a 45-year-old woman who had been diagnosed with Swyer syndrome at the age of 16 years. The patient underwent bilateral gonadectomy one year after the diagnosis due to the associated risk of developing malignancy and was treated since with hormone replacement therapy. At the age of 32 and 34 years, 2 successful IVF procedures were performed with oocyte donations. The pregnancies proceeded without any complications and both were resolved by caesarean section. The healthy sons' weights were $3600 \mathrm{~g}$ and $3700 \mathrm{~g}$, respectively.
\end{abstract}

Key words: Swyer syndrome, primary amenorrhoea, in-vitro fertilization.

\section{Introduction}

Swyer syndrome, also known as complete $X Y$ gonadal dysgenesis, is classified as a disorder of sex development (DSD) and is associated with female infertility. It was first described by Swyer in 1955 [1]. The incidence of this rare condition is estimated to be approximately 1 per 80,000 births [2]. 10-20\% of cases are caused by a mutation in the SRY gene, but the involvement of other genes has also been proven. The mutation can be both spontaneous and inherited. The inheritance pattern depends on the causative gene [3]. Familial Swyer syndrome cases have also been reported in the literature, but they are very rare and spontaneous [4]. Delayed diagnosis is frequently observed, even though the symptoms are characteristic. Most patients do not have any symptoms until adolescence, when they present with delayed puberty and primary amenorrhoea. The appearance of external genitalia is phenotypically female, and imaging procedures reveal small uterus, fallopian tubes, and non-functional fibrous tissue in the gonadal location [5]. Decreased levels of oestrogens caused by insufficient, aplastic, streak gonads are the cause of deficient breast development, and narrow pelvis and hips. Such a diagnosis is also associated with increased risk of osteoporosis, cardiovascular diseases, and most importantly gonadoblastoma or even dysgerminoma development in dysgenetic gonads. Treatment of this condition is based on hormone replacement therapy (HRT) containing oestrogens and progestins. The procedure of bilateral gonadectomy, after diagnosis of $46, \mathrm{XY}$ gonadal dysgenesis, is also performed to prevent development of a gonadal tumour [6]. Patients with Swyer syndrome are characterized by a female phenotype, mostly female psychological gender, and male karyotype. Even though infertility resulting from the inability of the aplastic gonads to exhibit gametogenesis is a common problem among individuals with Swyer syndrome, oocyte donation is an effective method of fertilization, which enables affected women to become pregnant and prevents the condition being passed to offspring in hereditary cases.

\section{Case report}

In 1990 a 16-year-old patient presented for the first time to the gynaecological endocrinology clinic with primary amenorrhoea. The clinical examination revealed 
features of delayed puberty. In order to determine the cause of the symptoms, chromosomal analysis was performed, which revealed a 46, XY karyotype. Swyer syndrome was diagnosed based on results of laboratory, imaging, and genetic tests. At the age of 17 years the patient underwent bilateral gonadectomy due to the diagnosis and the associated risk of developing malig nancy. Hormone replacement therapy was implemented, and regular follow-up visits were recommended. The patient periodically underwent standard diagnostic procedures. Cytology, imaging, and laboratory tests were then performed including hormonal, hepatic, and lipid profile, glucose, coagulogram, and pelvic ultrasound. Breast ultrasound examination was performed not only due to HRT control but also because of the presence of breast cancer in the patient's family history. Several irregularities were detected during control visits. In 1999, she complained of outbreak symptoms. A T-score of - 1.1 was obtained in the bone density test at the lumbar spine carried out in 2007.

At the age of 32 years, the patient underwent an IVF procedure with oocyte donation. Before the embryo transfer, she was taking progesterone and oestrogen for endometrial preparation. The patient's sister oocytes were fertilized with her husband's prepared spermatozoa. The procedure was successful. She commenced micronized progesterone vaginally $200 \mathrm{mg} 2$ times daily until the end of the first trimester The pregnancy proceeded without any complications. Due to lack of labour progress, the pregnancy was resolved by caesarean section in the $40^{\text {th }}$ week of gestation and a healthy son was delivered. The baby's weight was $3600 \mathrm{~g}$ with an Apgar score of 10. Two years later, a second successful IVF procedure was carried out. The earlier introduction of progesterone and oestrogen allowed the patient to be prepared for the embryo transfer. Vaginal micronized progesterone $200 \mathrm{mg}$ twice a day was implemented during the first trimester. A caesarean section was eventually performed because of the presence of a periurethral abscess. A healthy male neonate was delivered in the 39th week of gestation. The newborn weighed $3700 \mathrm{~g}$ and scored 10 on the Apgar test. The perinatal outcome was uneventful.

In a recent check-up visit, at the age of 45 years, the patient presented to the gynaecological endocrinology clinic with very light menstrual bleeding. In routine diagnostic procedures several abnormalities in laboratory test results were found. The increased FSH level was at $87.32 \mathrm{mIU} / \mathrm{mL}$ ( $\mathrm{LH}-45.3 \mathrm{mIU} / \mathrm{mL}$ ), and a decreased level of oestradiol was recorded: $16 \mathrm{pg} / \mathrm{mL}$. The lipid profile showed total cholesterol level at $5.06 \mathrm{mmol} / \mathrm{L}$ (normal level below $4.9 \mathrm{mmol} / \mathrm{L}$ ) and neutral fats at $1.8 \mathrm{mmol} / \mathrm{L}$ (normal level below $1.7 \mathrm{mmol} / \mathrm{L}$ ). Transvaginal ultrasound results revealed no abnormalities. An anteflexed uterus with homogeneous structure $(48 \times 30 \mathrm{~mm})$ was visualised and the was $4 \mathrm{~mm}$ thick. Medical hormone preparations containing $2 \mathrm{mg}$ oestradiol with $10 \mathrm{mg}$ dydrogesterone were prescribed. The patient was discharged home with the next control appointment scheduled within 1 year.

\section{Discussion}

Even though the clinical picture is characteristic, and diagnostic methods such as detailed clinical evaluation, and karyotype and imaging tests are commonly available, a delay in reaching an accurate diagnosis is frequently observed. In the case of the presented patient, the diagnosis of Swyer syndrome was made early. At the age of 17 years the patient received appropriate treatment, which significantly improved the prognosis for enabling future pregnancies by the proper development of reproductive organs and the prevention of health complications of hypoestrogenism. She underwent a bilateral gonadectomy due to a high risk of gonad-located neoplastic processes associated with Swyer syndrome. The diagnosis of complete $X Y$ gonadal dysgenesis puts patients at high risk of health problems such as bone fractures and future osteoporosis, cardiovascular diseases, and the psychological reaction of a young person facing the prospect of difficulties in conception. That can lead to a decreased mood and even depressive syndromes. Moreover, such a diagnosis is associated with an increased predisposition for gonadoblastoma or dysgerminoma developing in dysgenetic gonads. This risk ranges from $30-75 \%$ of all females with pure gonadal dysgenesis. On this account, surgical bilateral gonadectomy is the procedure of choice. In some cases, chemotherapy and radiotherapy could be an appropriate way to treat dysgerminoma because of its high sensitivity to this therapeutic option [7]. Early diagnosis based upon a detailed clinical evaluation, the karyotype, and imaging tests is crucial because the introduction of hormonal replacement therapy allows the induction of menstrual bleeding and enlarges the uterus and reproductive tract. In addition, the risk of osteoporosis or cardiovascular sequelae is reduced, and most importantly there is a possibility to prevent cancer development by removing the gonads [8].

An extremely important factor is properly performed differential diagnosis. In differentiating the causes of primary amenorrhea in phenotypic females, the Mayer-Rokitansky-Küster-Hauser syndrome must be taken into consideration. Correctly developed ovaries and a XX karyotype distinguish it from Swyer syndrome [9]. Complete androgen insensitivity syndrome is another possible diagnosis in such cases. The karyotype observed in that syndrome is $\mathrm{XY}$, as well as in Swyer syndrome, but imaging procedures reveal the presence of testicles and a lack of uterus in these patients [10]. The selection of patients with Swyer syndrome from the group presenting with primary amenorrhoea allows for early implementation of the therapy with all the 
Table 1. Case reports of pregnancies in $46 \mathrm{XY}$ females complications during pregnancies and method of childbirth

\begin{tabular}{|c|c|c|c|c|}
\hline Study & $\begin{array}{c}\text { No. of } \\
\text { patients }\end{array}$ & $\begin{array}{l}\text { Single or multiple } \\
\text { pregnancy }\end{array}$ & Pregnancy complication & Method of childbirth \\
\hline Sauer et al. & 1 & Twin & Preeclampsia & Caesarean section \\
\hline Cornet et al. & 3 & Single & No complications & Caesarean section \\
\hline Bardeguez et al. & 1 & Triple & Information not available & Information not available \\
\hline Bianco et al. & 1 & Information not available & Information not available & Information not available \\
\hline Kan et al. & 1 & $1^{\text {st }}$ single, $2^{\text {nd }}$ twin & Gestational hypertension & Caesarean section \\
\hline Dirnfeld et al. & 2 & Single and twin & No complications & Caesarean section \\
\hline Selvaraj et al. & 1 & Single & No complications & Caesarean section \\
\hline Chen et al. & 1 & Twin & No complications & Caesarean section \\
\hline Ko et al. & 1 & Triple & One hydatidiform mole and preeclampsia & Caesarean section \\
\hline Plante et al. & 1 & Single & No complications & Caesarean section \\
\hline Siddique et al. & 1 & Single & No complications & Vaginal delivery \\
\hline Tulic et al. & 1 & Single & Reduced amniotic fluid & Caesarean section \\
\hline Creatsas et al. & 1 & Single & Gestational hypertension & Caesarean section \\
\hline Shah et al. & 1 & Twin & Preeclampsia & Information not available \\
\hline Taneja et al. & 1 & Single & No complications & Caesarean section \\
\hline Gupta et al. & 2 & Single & $1^{\text {st }}-$ no complications, $2^{\text {nd }}-$ during pregnancy & Information not available \\
\hline
\end{tabular}

benefits, and also leaves the possibility of pregnancy thanks to the IVF with oocyte donation.

It is very important to take care of the mental health of patients exposed to the prospect of infertility or the necessity to undertake medical procedures aiding the process of conceiving. The impact of, usually unexpected, a diagnosis of Swyer syndrome on the psychological condition of the patients must be taken into consideration. According to Danish, some patients can even struggle with suicidal thoughts [11]. Therefore, to allow patients to adapt to and accept their condition, it is necessary to provide appropriate psychological management.

The literature provides few case reports of patients with a hypoplastic uterus due to complete $X Y$ gonadal dysgenesis, in which pregnancies were achieved through the use of hormone therapy and assisted reproductive techniques [12-27]. We found 16 papers from 1989 to 2019 presenting a total of 20 women who became pregnant and managed to deliver (Table 1). Gonads of patients with this syndrome do not perform proper gametogenesis; therefore, IVF with oocyte donation is an effective method of fertilization, which also prevents passing a disease to an offspring in cases with hereditary mutation. The success of such procedures is directly related to the early implementation of hormonal treatment. It enables the proper development of the patient's reproductive organs, that in inadequately treated patients, are often not developed enough to allow the patient to maintain a pregnancy. Caesarean section is a preferred method of delivery because there is no medical evidence of uterine dilatation efficacy in patients with Swyer syndrome and the feasibility of natural delivery [28].

\section{Conclusions}

The value of diligently conducted patient monitoring, just like in our patient - through regularly performed follow-up visits and necessary tests - is inestimable. It enables not only the prevention of treatment complications, but also allows the monitoring of their health and helps to detect any health problems related to the underlying disease as early as possible.

\section{Disclosure}

The authors report no conflict of interest.

\section{References}

1. Swyer GIM. Male pseudohermaphroditism: a hitherto undescribed form. Br Med J 1955; 2: 709-712.

2. Dural O, Evruke I, Can S, Yasa C, Ugurlucan FG, Akhan SE. Atypical presentation of Swyer syndrome. J Pediatr Adolesc Gynecol 2019; 32: 645-647.

3. King TF, Conway GS. Swyer syndrome. Curr Opin Endocrinol Diabetes Obes 2014; 21: 504-510.

4. Banoth M, Naru RR, Inamdar MB, Chowhan AK. Familial Swyer syndrome: a rare genetic entity. Gynecol Endocrinol 2018; 34: 389-393.

5. Michala L, Goswami D, Creighton SM, Conway GS. Swyer syndrome: presentation and outcomes. BJOG 2008; 115: 737-741.

6. Milewicz T, Mrozińska S, Szczepański W, et al. Dysgeminoma and gonadoblastoma in the course of Swyer syndrome. Pol J Pathol 2016; 67: 411-414.

7. Jorgensen PB, Kjartansdóttir KR, Fedder J. Care of women with XY karyotype: a clinical practice guideline. Fertil Steril 2010; 94: 110-111.

8. Freitas F, Sousa C, Salazar C. Male pseudohermaphroditism (in Portuguese). J SOBRAGE 2001; 16: 2-3.

9. Oppelt P, Renner SP, Kellermann A, et al. Clinical aspects of Mayer-Rokitansky-Küster-Hauser syndrome: recommendations for clinical diagnosis and staging. Hum Reprod 2006; 21: 792.

10. Meyer KF, Freitas Filho LG, Silva KI, et al. The XY female and SWYER syndrome. Urol Case Rep 2019; 26: 100939. 
11. Johannsen TH, Ripa CP, Mortensen EL, et al. Quality of life in 70 women with disorders of sex development. Eur J Endocrinol 2006; 155: 877-885.

12. Sauer MV, Lobo RA, Paulson RJ. Successful twin pregnancy after embryo donation to a patient with XY gonadal dysgenesis. Am J Obstet Gynecol 1989; 161: 380-381.

13. Cornet D, Alvarez S, Antoine JM, et al. Pregnancies following ovum donation in gonadal dysgenesis. Hum Reprod 1990; 5: 291-293.

14. Bardeguez AD, de Ziegler D, Weiss G. Multifetal pregnancy in a gonadal dysgenesis mosaic. Obstet Gynecol 1990; 76: 502-504.

15. Bianco S, Agrifoglio V, Mannino F, Cefalu E, Cittadini E. Successful preg nancy in a pure gonadal dysgenesis with karyotype 46, XY patient (Swyer's syndrome) following oocyte donation and hormonal treatment. Acta Eur Fertil 1992; 23: 37-38.

16. Kan AK, Abdalla HI, Oskarsson T. Two successful pregnancies in a 46, XY patient. Hum Reprod 1997; 12: 1434-1435.

17. Dirnfeld M, Bider D, Abramovicia H, Calderon I, Blumenfeld Z. Subsequent successful pregnancy and delivery after intracytoplasmic sperm injection in a patient with XY gonadal dysgenesisms. Eur J Obstet Gynecol Reprod Biol 2000; 88: 101-102.

18. Selvaraj K, Ganesh V, Selvaraj P. Successful pregnancy in a patient with a 46, XY karyotype. Fertil Steril 2002; 78: 419-420.

19. Chen MJ, Yang JH, Mao TL, Ho HN, Yang YS. Successful pregnancy in a gonadectomized woman with $46, \mathrm{XY}$ gonadal dysgenesis and gonadoblastoma. Fertil Steril 2005; 84: 217.

20. Ko PC, Peng HH, Soong YK, Chang SD. Triplet pregnancy complicated with one hydatidiform mole and preeclampsia in a 46, XY female with gonadal dysgenesis. Taiwan J Obstet Gynecol 2007; 46: 276-280.

21. Plante BJ, Fritz MA. A case report of successful pregnancy in a patient with pure 46, XY gonadal dysgenesis. Fertil Steril 2008; 90: 2015.e1-2.

22. Siddique H, Daggett P, Artley K. Successful term vaginal delivery in a 46 , XY woman. Int J Gynaecol Obstet 2008; 101: 298-299.

23. Tulic I, Tulic L, Micic J. Pregnancy in patient with Swyer syndrome. Fertil Steril 2011; 95: 1789.e1-2.

24. Creatsas G, Deligeoroglou E, Tsimaris P, Pantos K, Kreatsa M. Successful pregnancy in a Swyer syndrome patient with preexisting hypertension. Fertil Steril 2011; 96: e83-85.

25. Shah JS, Viteri OA, Longo M, et. al. Twin gestation in a Swyer syndrome patient with superimposed pre-eclampsia. J Obstet Gynecol 2018; 38: 719-720.

26. Taneja J, Ogutu D, Ah-Moye M. Rare successful pregnancy in a patient with Swyer Syndrome. Case Rep Womens Health 2016; 12: 1-2.

27. Gupta A, Bajaj R, Jindal UN. A rare case of Swyer syndrome in two sisters with successful pregnancy outcome in both. J Hum Reprod Sci 2019; 12: 267-269.

28. Polakova M, Alexander D, Sulc J, et al. Pregnancy and delivery in a patient with pure 46, XY karyotype. Summary of actual knowledge about XY women. Ceska Gynekol 2013; 78: 443-447. 